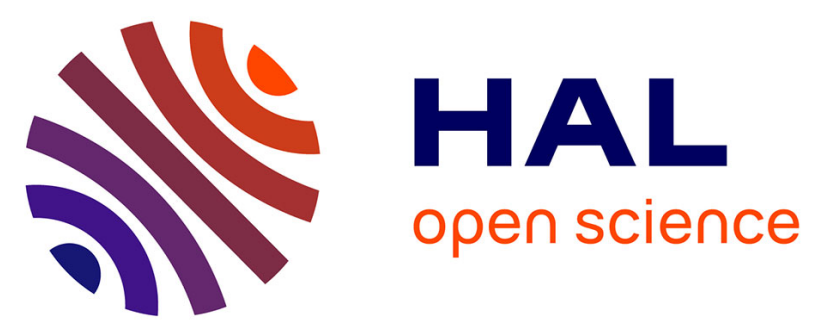

\title{
The nuclear appearance of ERK1/2 and p38 determines the sequential induction of ATF2-Thr71 and ATF2-Thr69 phosphorylation by serum in JNK-deficient cells
}

Bart Baan, Gerard C.M. van Der Zon, J. Antonie Maassen, D. Margriet

Ouwens

\section{To cite this version:}

Bart Baan, Gerard C.M. van Der Zon, J. Antonie Maassen, D. Margriet Ouwens. The nuclear appearance of ERK1/2 and p38 determines the sequential induction of ATF2-Thr71 and ATF2-Thr69 phosphorylation by serum in JNK-deficient cells. Molecular and Cellular Endocrinology, 2009, 311 (1-2), pp.94. 10.1016/j.mce.2009.07.023 . hal-00521554

\author{
HAL Id: hal-00521554 \\ https://hal.science/hal-00521554
}

Submitted on 28 Sep 2010

HAL is a multi-disciplinary open access archive for the deposit and dissemination of scientific research documents, whether they are published or not. The documents may come from teaching and research institutions in France or abroad, or from public or private research centers.
L'archive ouverte pluridisciplinaire HAL, est destinée au dépôt et à la diffusion de documents scientifiques de niveau recherche, publiés ou non, émanant des établissements d'enseignement et de recherche français ou étrangers, des laboratoires publics ou privés. 


\section{Accepted Manuscript}

Title: The nuclear appearance of ERK1/2 and p38 determines the sequential induction of ATF2-Thr71 and ATF2-Thr69 phosphorylation by serum in JNK-deficient cells

Authors: Bart Baan, Gerard C.M. van der Zon, J. Antonie Maassen, D. Margriet Ouwens

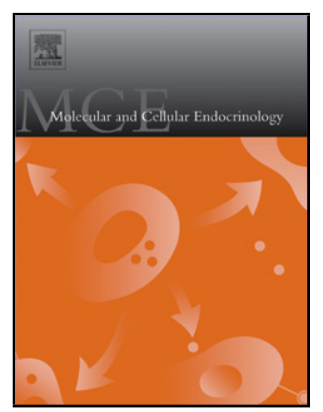

PII: S0303-7207(09)00396-7

DOI: doi:10.1016/j.mce.2009.07.023

Reference: MCE 7273

To appear in: $\quad$ Molecular and Cellular Endocrinology

Received date: 30-3-2009

Revised date: $\quad$ 15-7-2009

Accepted date: $\quad$ 22-7-2009

Please cite this article as: Baan, B., van der Zon, G.C.M., Maassen, J.A., Ouwens, D.M., The nuclear appearance of ERK1/2 and p38 determines the sequential induction of ATF2-Thr71 and ATF2-Thr69 phosphorylation by serum in JNK-deficient cells, Molecular and Cellular Endocrinology (2008), doi:10.1016/j.mce.2009.07.023

This is a PDF file of an unedited manuscript that has been accepted for publication. As a service to our customers we are providing this early version of the manuscript. The manuscript will undergo copyediting, typesetting, and review of the resulting proof before it is published in its final form. Please note that during the production process errors may be discovered which could affect the content, and all legal disclaimers that apply to the journal pertain. 
REVISED VERSION MCE-D-09-00112

\section{RESEARCH PAPER}

The nuclear appearance of ERK1/2 and p38 determines the sequential induction of ATF2-Thr71 and ATF2-Thr69 phosphorylation by serum in JNK-deficient cells

Bart Baan ${ }^{\mathrm{a}}$, Gerard C.M. van der Zon ${ }^{\mathrm{a}}$, J. Antonie Maassen ${ }^{\mathrm{a}, \mathrm{b}}$ and D. Margriet Ouwens ${ }^{\mathrm{a}, *}$

${ }^{a}$ Department of Molecular Cell Biology, Section Signal Transduction and Ageing, Leiden University Medical Centre, Leiden, The Netherlands

${ }^{\mathrm{b}}$ Department of Endocrinology/Diabetes Centre, VU University Medical Centre, Amsterdam, The Netherlands

* Corresponding author at: Department of Molecular Cell Biology, Section Signal Transduction and Ageing, Leiden University Medical Centre, Postzone S1-P, PO Box 9600, 2300 RC Leiden, The Netherlands

Phone: +31 71526 9268; fax: +31 715268270

e-mail address: d.m.ouwens@lumc.nl

keywords: ATF2, ERK1/2, p38, fibroblasts, serum 
Growth factors activate ATF2 via sequential phosphorylation of Thr69 and Thr71, where the ATF2-Thr71-phosphorylation precedes the induction of ATF2-Thr69+71phosphorylation. Here, we studied the mechanisms contributing to serum-induced two-step ATF2-phosphorylation in JNK1,2-deficient embryonic fibroblasts. Using anion exchange chromatography, ERK1/2 and p38 were identified as ATF2-kinases in vitro. Inhibitor studies as well as nuclear localization experiments show that the sequential nuclear appearance of ERK1/2 and p38 determines the induction of ATF2Thr71 and ATF2-Thr69+71-phosphorylation in response to serum. 


\section{Introduction}

ATF2 is a ubiquitously expressed member of the cAMP-responsive element (CRE)-binding protein family of basic region-leucine zipper (bZIP) transcription factors also including CREB (Mayr et al., 2001) and ATF3, ATF4, ATF6 and B-ATF (Hai et al., 2001; Hai et al., 1989). ATF2 can form homo- and heterodimers with other ATF-family members (Hai et al., 1989), but also with the activating protein-1 (AP-1) family member cJun (Hai et al., 1991). The various dimer compositions confer an enormous repertoire of target genes on ATF2, which include cell cycle regulators, proteins involved in invasion or adhesion, growth factors and pro-inflammatory cytokines, DNA repair genes, transcriptional factors, and molecules associated with metabolic control (Bhoumik et al., 2007; Vlahopoulos et al., 2008).

In the absence of a stimulus, ATF2 is held in an inactive conformation (Li et al., 1996). Phosphorylation of residues within the activation domain leads to ATF2 transcriptional activation (Ban et al., 2000; Sakurai et al., 1991; Sevilla et al., 2004). In particular, phosphorylation of two threonine (Thr) residues, Thr69 and Thr71, is required and sufficient for transcriptional activation of ATF2 (Livingstone et al., 1995; van Dam et al., 1995).

Both inducers of cellular stress, like pro-inflammatory cytokines, oncogenes, viruses, heat shock, osmotic stress, and DNA-damaging agents as well as growth factors, increase the transactivation capacity of ATF2 through phosphorylation of the Thr69 and Thr71 residues by the stress activated protein kinases c-jun N-terminal kinase (JNK) and p38 (Kyriakis et al., 2001). The mechanism of ATF2 activation by mitogens is markedly different from that by inducers of cellular stress (Ouwens et al., 2002; van Dam et al., 2001). In contrast to cellular stresses, mitogens are poor activators of JNK and p38 (Kyriakis et al., 2001). Furthermore, cellular stresses induce a prolonged phosphorylation of ATF2, whereas the activation induced by growth factors is much more transient, and, importantly, is elicited via a two-step mechanism (Ouwens et al., 2002). Within minutes after the addition of growth factors, phosphorylation of ATF2-Thr71 is induced, whereas subsequent phosphorylation of ATF2-Thr69 occurs several minutes later (Baan et al., 2006; Ouwens et al., 2002). Finally, in contrast to inducers of cellular stress, like osmotic shock and methyl methane sulfonate, the phosphorylation and activation of ATF2 by insulin and epidermal growth factor (EGF) is dependent on Ras. Ras regulates the activation of ATF2 via two distinct effector pathways (Ouwens et al., 2002). Activation of the RafMEK-ERK1/2-pathway directs the phosphorylation of ATF2 on Thr71, which occurs within 2-4 minutes after growth factor addition (Baan et al., 2006; Ouwens et al., 2002). Importantly, ERK1/2 is unable to phosphorylate ATF2 on Thr69 (Morton et al., 2004; Ouwens et al., 2002), and the induction of subsequent ATF2-Thr69 phosphorylation in response to insulin and EGF was found be dependent on the Raseffector RalGDS (Ouwens et al., 2002). The RalGDS-mediated increase in GTPbound Ral contributes to the Src-dependent activation of p38 and JNK (De Ruiter et al., 2000; Ouwens et al., 2002). These low levels of JNK and p38 induced by mitogens were found to be essential and sufficient to efficiently phosphorylate ATF2 on Thr69 when ATF2 is already phosphorylated on Thr71 by ERK1/2 (Ouwens et al., 2002).

Studies on fibroblasts indicate that the activation of JNK by insulin is paralleled by nuclear translocation of the activated protein kinase, and that the nuclear appearance of JNK is rate-limiting for the induction of ATF2-Thr69 phosphorylation (Baan et al., 2006). Although p 38 was found to be essential for growth factor induced 
ATF-Thr69 phosphorylation in JNK1,2-deficient embryonic fibroblasts, insulin failed to induce nuclear translocation of phosphorylated p38 in 'JNK-containing' fibroblasts (Baan et al., 2006).

In the current study, we used JNK1,2-deficient fibroblasts to further clarify the involvement of $\mathrm{p} 38$ in the induction of ATF2-phosphorylation by growth factors. First, ATF2 kinase(s) were purified from serum-treated cells by anion exchange chromatography. Then, using pharmacological inhibitors, and nuclear localization experiments, we further detailed the role of the purified kinases in the serum-mediated induction of ATF2-Thr71 and ATF2-Thr69+71-phosphorylation, respectively.

\section{Materials and Methods}

\subsection{Cell culture and cell stimulation}

JNK1,2-/- (JNK8) cells are immortalized embryonic fibroblasts derived from derived from mouse JNK 1 and 2 double knockout embryos using the 3 T3 protocol, and have been described previously (Ouwens et al., 2002; Sabapathy et al., 2004). Cells were cultured in Dulbecco's modified Eagle's medium (DMEM) containing 9\% fetal bovine serum (FBS) and antibiotics. Before cell-stimulations, the cells were serum-starved (DMEM w/ 0.5\% FBS) for 16h. When inhibitors were used, cells were pre-treated for 30 minutes with $2.5 \mu \mathrm{M} \mathrm{SB} 203580$ (Promega) or for 15 minutes with $10 \mu \mathrm{M} \mathrm{U} 0126$ (Promega), before addition of serum (FCS) to $20 \%$.

\subsection{Transient transfections and luciferase assays}

For protein phosphorylation experiments, JNK1,2-/- cells were transfected in 6-well plates with a total of $1.125 \mu \mathrm{g}$ DNA per well: $0.125 \mu \mathrm{g}$ of either pMT2 or expression vectors encoding constitutively active RasL61, RafCAAX, or RIfCAAX, $0.5 \mu \mathrm{g}$ pMT2-HA-ATF2 and $0.5 \mu \mathrm{g}$ pMT2-HA-p38 using Fugene6 transfection reagent (Roche) as described previously (Baan et al., 2006; Ouwens et al., 2002). For luciferase assays, JNK1,2-/- cells were transfected in 6-well plates using the DEAEdextran method as described (Baan et al., 2006; Ouwens et al., 2002). For each well $0.25 \mu \mathrm{g}$ of pGl3-GAL4-E4-luciferase reporter was co-transfected with $2 \mu \mathrm{g}$ of either pMT2, or expression vectors encoding constitutively active RasL61, RafCAAX, or RlfCAAX, and $2 \mu \mathrm{g}$ of pC2-GAL4-ATF2-TAD, either wild type or T69/71A (Baan et al., 2006; Ouwens et al., 2002). Cells were serum-starved 8 hours after transfection and harvested 24 hours later for analysis of luciferase activity (Baan et al., 2006; Ouwens et al., 2002).

\subsection{Western blot analysis and antibodies}

Whole cell lysates were prepared from $9 \mathrm{~cm}$ dishes that were rinsed twice with ice-cold phosphate-buffered saline (PBS) and lysed in $750 \mu$ l Laemmli sample buffer. Proteins were separated on polyacrylamide slab gels and transferred to Immobilon (Millipore). Blots were stained with Ponceau S before blocking to verify equal loading and appropriate protein transfer. Filters were incubated with antibodies as described previously (Ouwens et al., 2002). The antibodies used were: Lamin A and phospho-specific ATF2-Thr69+71, ATF2-Thr71, p38-Thr180/Tyr182, ERK1/21/2Thr202/Tyr204 and MAPKAPK2-P (all polyclonal, Cell Signaling); p38 (N-20), 
ATF2 (C-19) and ERK1/21 (K-23) (polyclonals, Santa Cruz) and monoclonal anti-HA antibody 16B12 (BabCO) and anti-GST (Amersham Pharmacia Biotech). Secondary antibodies: goat anti-rabbit and goat anti-mouse IgG-HRP conjugate were from Promega. The elongation factor (EF)-1 $\beta$ antibody was described previously (Sanders et al., 1996). The specificity of the phospho-specific ATF2 antibodies (P71 and P69+71) has been verified previously (Morton et al., 2004; Ouwens et al., 2002) .

\subsection{MonoQ/anion-exchange chromatography}

Anion-exchange chromatography was performed essentially as described previously (Ouwens et al., 2002). Briefly, stimulated cells were scraped in MonoQ lysis buffer [20 mM Tris (pH 7.0), 0.27 M sucrose, $1 \mathrm{mM}$ EDTA, $1 \mathrm{mM}$ EGTA, $1 \%$ Triton $\mathrm{X}-100,10 \mathrm{mM}$ sodium $\beta$-glycerolphosphate, $50 \mathrm{mM} \mathrm{NaF}, 5 \mathrm{mM}$ sodium pyrophosphate, $1 \mathrm{mM}$ sodium orthovanadate, $0.1 \%$ (v/v) $\beta$-mercaptoethanol and Complete protease inhibitors (Roche Biochemicals)]. Lysates of six 9-cm dishes ( 8000 mg protein) were diluted twofold with MonoQ buffer [50 mM Tris.Cl (pH 7.5), $1 \mathrm{mM}$ EDTA, $1 \mathrm{mM}$ EGTA, 5\% (v/v) glycerol, 0.03\% (w/v) Brij-35, $1 \mathrm{mM}$ benzamidine, $0.3 \mathrm{mM}$ sodium orthovanadate, and $0.1 \%$ (v/v) $\beta$-mercaptoethanol] and applied to a MonoQ HR 5/5 column (Amersham Pharmacia Biotech) equilibrated in MonoQ buffer. After washing, the column was developed with a linear salt gradient to $700 \mathrm{mM} \mathrm{NaCl}$ in MonoQ buffer and fractions of $1 \mathrm{ml}$ were collected. Aliquots of 10 $\mu \mathrm{l}$ from each fraction were used in in vitro ATF2 kinase assays.

\subsection{Preparation of cellular fractions}

For cell fractionation experiments, lysates were prepared from $9 \mathrm{~cm}$ dishes that were rinsed twice with ice-cold phosphate buffered saline (PBS) and scraped in 1 $\mathrm{ml}$ of cold RIPA buffer [30 mM Tris- $\mathrm{HCl} \mathrm{pH} 7.5,1 \mathrm{mM}$ EDTA, $150 \mathrm{mM} \mathrm{NaCl}, 0.5 \%$ Triton X-100, $0.5 \%$ Na-DOC, $1 \mathrm{mM}$ sodium orthovanadate, $10 \mathrm{mM}$ sodium fluoride and Complete protease inhibitors (Roche)]. Nuclei were pelleted by centrifugation (10 min, $14000 \mathrm{rpm}, 4^{\circ} \mathrm{C}$ ). Supernatants were collected and stored as cytosolic fractions. Nuclear pellets were washed twice with RIPA and Laemmli buffer was added. Before western blotting nuclear samples were sonicated and boiled. Purity of the cell fractions was checked by Western Blotting, using EF-1 $\beta$ and Lamin A antibodies as cytosolic and nuclear markers, respectively.

\subsection{ATF2 kinase assays}

For in vitro ATF2 kinase assays, equal volumes of MonoQ-fractions were incubated at $30^{\circ} \mathrm{C}$ with $2 \mu \mathrm{g}$ of purified GST-ATF2-N substrate (van Dam et al., 1995) and $50 \mu \mathrm{M}$ ATP in a total volume of $60 \mu \mathrm{l}$ of kinase buffer $[25 \mathrm{mM}$ HEPES, $\mathrm{pH} 7.4,25 \mathrm{mM} \mathrm{MgCl} 2,25 \mathrm{mM} \beta$-glycerolphosphate, $5 \mathrm{mM} \beta$-mercaptoethanol and $100 \mu \mathrm{M}$ sodium orthovanadate]. When indicated, kinase assays were performed in the presence of vehicle (DMSO) or inhibitor SB203580 $(2.5 \mu \mathrm{M})$. Reactions were terminated by the addition of $20 \mu \mathrm{l}$ of $4 \mathrm{x}$ Laemmli buffer and subsequently analyzed by SDS-PAGE/immunoblotting with phospho-specific ATF2-Thr71 antibodies. Blots were quantitated using Scion Image software.

\subsection{Immunofluorescence}


Cells were grown on coverslips. After stimulation, cells were washed twice with ice-cold PBS and subsequently fixed in $3.7 \%$ formaldehyde in PBS for 15 minutes at room temperature. Coverslips were washed with Tris buffered saline [TBS; $25 \mathrm{mM}$ Tris, $\left.100 \mathrm{mM} \mathrm{NaCl}, 5 \mathrm{mM} \mathrm{KCl}, 0.7 \mathrm{mM} \mathrm{CaCl} 2.2 \mathrm{H}_{2} \mathrm{O}, 0.5 \mathrm{MgCl}_{2} .6 \mathrm{H} 2 \mathrm{O}\right]$ and permeabilised for 5 minutes with $0.1 \%$ Triton X-100 in TBS, subsequently washed with $0.2 \% \mathrm{BSA} / \mathrm{TBS}$, blocked for 30 minutes in $2 \% \mathrm{BSA} / \mathrm{TBS}$ at room temperature and then incubated overnight at $4{ }^{\circ} \mathrm{C}$ with primary antibodies diluted $1: 250$ in $0.2 \%$ BSA/TBS. After $0.2 \%$ BSA/TBS washes, coverslips were incubated with appropriate secondary antibodies diluted 1:100 in $0.2 \%$ BSA/TBS for $2 \mathrm{hrs}$ at room temperature. Thereafter coverslips were washed sequentially with $0.2 \%$ BSA/TBS and TBS, mounted in DAPI-containing Vectashield solution (Vector Laboratories) and fixed with nail polish. Fluorescence was detected using a Leica DM-RXA microscope. Pictures were acquired as color images (MERGE) and prepared using Photopaint and Coreldraw software.

\section{Results}

3.1. The main ATF2 N-terminal kinase activities co-purify with ERK1/2 and p38 in serum-stimulated JNK1,2 -/- cells

To identify ATF2-kinases in JNK1,2-/- cells, cell lysates prepared after $10 \mathrm{~min}$ of serum stimulation were fractionated by anion-exchange chromatography on monoQ columns. Analysis of the obtained fractions showed that the bulk of ATF2-directed kinase activity co-purified with fractions containing ERK1/2. A smaller peak of ATF2-directed kinase activity was recovered in a fraction co-purifying with p38 (Fig. 1A, solid line).

Incubation of the cells with U0126, an inhibitor of the upstream activator of ERK1/2, MEK1/2, (Favata et al., 1998), strongly reduced the serum-induced ATF2 kinase activity in the fractions co-purifying with ERK1/2 (Fig. 1A, dashed line). Furthermore, addition of the p38 inhibitor SB203580 (Cuenda et al., 1995) to the in vitro kinase assay completely blocked ATF2-kinase activity in the fraction copurifying with p38 (Fig. 1B). Similar results were obtained for JNK1,2-/- cells treated with EGF (data not shown). Thus, the major ATF2-directed kinase activities in growth factor stimulated JNK1,2-/- cells are represented by ERK1/2 and p38.

3.2. Inhibition of ERK1/2 and p38 differentially abrogates ATF2-Thr71 and ATF2Thr69+71 phosphorylation in serum-stimulated JNK1,2 -/- cells

As both ERK1/2 and p38 were identified as ATF2-directed kinases from JNK1,2-/- cells, we next analyzed the effects of U0126 and SB203580 on seruminduced ATF2-Thr71 and ATF2-Thr69+71 phosphorylation. Western blot analysis of lysates of JNK1,2-/- cells, showed that ATF2-Thr71 phosphorylation was induced after 2-4 min, whereas the onset of ATF2-Thr69+71 was detected at 4-6 min after serum addition (Fig. 2A).

The presence of U0126 delayed the onset of ATF2-Thr71 and ATF2Thr69+71 phosphorylation after serum addition (Fig. 2B/C). Furthermore, the level of both ATF2-Thr69+71 and ATF2-Thr71 phosphorylation observed 8 min after serum addition was markedly lower in the presence of U0126 (Fig. 2B). SB203580 
completely prevented serum-induced ATF2-Thr69+71 phosphorylation in JNK1,2-/cells, while slightly enhancing ATF2-Thr71 phosphorylation (Fig. 2B/C). The complete inhibition of the serum-induced phosphorylation of ERK1/2 and MAPKAPK-2 (Rouse et al., 1994), another downstream target of p38, confirmed effectiveness of U0126 and SB203580, respectively (Fig. 2D). These data show that ERK1/2 regulates the phosphorylation of ATF2 on Thr71, but also indicate that ERK1/2 is essential for maximal induction of ATF2-Thr69+71 phosphorylation by p38 in response to serum.

\subsection{Involvement of ERK1/2 and p38 in ATF2 activation in JNK1,2-/- cells}

Next, we examined whether the effects of upstream regulators of ERK1/2 and p38 on ATF2-phosphorylation in JNK1,2-/- cells. Previous reports showed that phorbol ester, a selective activator of the Raf-MEK-ERK1/2-pathway, can only phosphorylate ATF2 on Thr71, and fails to activate ATF2-dependent reporter genes ((Morton et al., 2004; Ouwens et al., 2002; van Dam et al., 1995). Accordingly, expression of RafCAAX: a constitutively active mutant of MEK's upstream activator Raf, in JNK1,2-/- cells increased ATF2-Thr71 phosphorylation, but had no significant effect on ATF2-Thr69+71 phosphorylation Fig. 3A). In contrast, expression of constitutively active RasL61 and RlfCAAX enhanced phosphorylation of ATF2 on Thr71 and Thr69+71, as well as p38 (Fig. 3A). Furthermore, both RasL61 and RlfCAAX activated a GAL4-ATF2 dependent luciferase reporter in a Thr69 and Thr71 dependent manner (Fig. 3B).

The inability of ERK1/2 to phosphorylate ATF2 on Thr69 raises the possibility that phosphorylation of ATF 2 on Thr69 by p38 occurs more efficiently when ATF2 is already phosphorylated on Thr71 by ERK1/2. To test this, monoQ fractions 12 and 17, containing active ERK and p38, respectively, were analyzed for their ability to phosphorylate ATF2 on Thr71 and Thr69+71. In line with previous findings, fraction 12 could only induce ATF2-Thr71 phosphorylation in vitro (Fig. 3C). Fraction 17 induced low levels of ATF2-Thr71 and ATF-Thr69+71 phosphorylation (Fig. 3C). However, ATF2 was very efficiently phosphorylated on Thr69+71 when a mixture of fractions 12 and 17 was added to the kinase reactions (Fig. 3C). Thus, ERK1/2 and p38 need to cooperate for efficient induction of ATF2 phosphorylation on Thr69 and Thr71 in response to mitogens and FCS.

\subsection{The onset of ATF2-Thr71 and ATF2-Thr69+71-phosphorylation associates with nuclear translocation of ERK1/2 and p38.}

Immunofluorescence experiments showed that phosphorylated ATF2 is localized in the nucleus, and confirmed that the p38 inhibitor SB203580 abolished serum-induced phosphorylation of ATF2-Thr69+71, but not of ATF2-Thr71 (Fig. 4). Serum stimulation of JNK1,2-/- cells induced the phosphorylation of both ERK1/2 and p38 within 2 minutes (Fig. 5A). As the MAPkinases involved in ATF2phosphorylation are simultaneously activated, their sequential role in ATF2phosphorylation cannot simply be explained by sequential activation. Therefore, we determined if differences in nuclear appearance of ERK1/2 and p38 might determine the differential onset of ATF2-Thr71 and ATF2-Thr69+71 phosphorylation.

Using cell fractionation and immunofluorescence procedures, we found that within 2 minutes, serum induced the nuclear translocation of phosphorylated ERK1/2 (Fig. 5B/6A) and that this was paralleled by the induction of ATF2-Thr71 
phosphorylation (Fig. 5B). Nuclear translocation of phosphorylated p38 was observed 4-6 minutes after serum addition and was paralleled by ATF2-Thr69+71 phosphorylation (Fig. 5B/6A). Purity of the cell fractions was checked by Western Blotting, using EF-1 $\beta$ and Lamin A antibodies as cytosolic and nuclear markers, respectively (Fig. 5C). Finally, the presence of SB203580 abrogated nuclear phosphop38 immunoreactivity found in response to serum (Figure 6B) and severely reduced the serum-induced phospho-ATF2-Thr69+71 and phospho-p38 signals in nuclear extracts (Figure 6C).

\section{Discussion}

The present study identifies the MAP kinases ERK1/2 and p38 as the major growth factor-induced ATF2-directed kinases in JNK1,2-/- cells and elucidates their role in two-step ATF2-phosphorylation mechanism in response to growth factors.

Using MonoQ anion exchange chromatography we found that, in JNK1,2-/cells, the major serum-induced ATF2-directed kinase activities co-purified with the ERK1/2 and p38 fractions. MonoQ separation of EGF- or insulin-stimulated JNKdeficient cell lysates resulted in similar ATF2-kinase profiles (data not shown), suggesting that these kinases are involved in general mitogenic signaling towards ATF2.

The role of ERK1/2 and p38 in serum-stimulated ATF2 phosphorylation in JNK-deficient fibroblasts was further established by inhibitor studies. Treatment of these cells with U0126 abolished the serum-induced ATF2-kinase activity in the ERK1/2-containing fractions and delayed the onset of ATF2 phosphorylation on Thr71 found in cell lysates. This suggests that ERK is the kinase responsible for the first phosphorylation of ATF2 on Thr71 in response to serum. We also observed that U0126 increased the activity in the p38-containing fraction. The reason for this increase is unknown. However, the increase in ATF2-kinase activity in fraction 17 was paralleled by a slightly increased phosphorylation of p38 in total cell extracts of JNK1,2-/- cells incubated with U0126 and serum (data not shown). Furthermore, the presence of SB203580 in the in vitro kinase reaction completely inhibited the ATF2kinase activity in fraction 17 . This suggests that $\mathrm{p} 38$ is the only kinase present in this fraction.

As ERK1/2 is incapable of phosphorylating ATF2 on Thr69 (Morton et al., 2004; Ouwens et al., 2002), cooperation with another kinase seems necessary for efficient ATF2-Thr69+71 phosphorylation. Our study identified p38 as the other ATF2-directed kinase in serum-treated JNK1,2-/- cells. p38 is known to be capable of phosphorylating ATF2 on both Thr69 and 71 residues (Morton et al., 2004; Ouwens et al., 2002; Raingeaud et al., 1995). In response to inducers of cellular stress the onset of ATF2-Thr69+71 coincides with the onset of ATF2-Thr71-phosphorylation, and this process seems completely p38-dependent in JNK-deficient cells (Morton et al., 2004; Ouwens et al., 2002). This raises the question whether activation of p38 alone may be sufficient for the induction of ATF2-phosphorylation in response to serum. Our data suggest that ERK1/2 activation is biologically relevant for serum-induced two-step ATF2-phosphorylation. In contrast to ERK1/2, the activity of p38 is low in serum-stimulated fibroblasts and, therefore, insufficient to phosphorylate ATF2 Thr71 and/or Thr69 efficiently by itself. However, these low levels of active p38 are essential and appear to be sufficient to phosphorylate Thr69 when ATF2 is already mono-phosphorylated on Thr71 by ERK1/2. Furthermore, recombinant p38 was 
reported to phosphorylate GST-ATF2 via a double collision mechanism in vitro (Waas et al., 2001). After the first (random) phosphorylation event of ATF2 on Thr69 or Thr71, p38 dissociates from the mono-phosphorylated ATF2 substrate. It then reassociates with ATF2 for phosphorylation of the second threonine. Importantly, the efficiency of the second phosphorylation step is differentially affected by the two mono-phosphorylated forms of ATF2: whereas Thr71-phosphorylated ATF2 was readily phosphorylated on Thr69, ATF2 mono-phosphorylated on Thr69 was found to be an inefficient substrate for p38-mediated Thr71- phosphorylation. Thus, efficient phosphorylation of ATF2 by recombinant active p38 only occurs in the order Thr71 $\rightarrow$ Thr69+71. In our JNK-deficient system, phosphorylation of ATF2-Thr71 by ERK1/2 might prime ATF2 for subsequent efficient ATF2-Thr69-phosphorylation by p38. Accordingly, inhibiting p38 activity reduced the ATF2-directed activity present in p38-containing MonoQ fraction and abolished the serum-induced ATF2-Thr69 phosphorylation found in JNK1,2-/- cell lysates. These findings suggest that in these cells, ERK1/2 and p38 cooperate to efficiently phosphorylate ATF2 on Thr69 and Thr71.

Finally, localization studies using cell fractioning and immunofluorescence experiments showed that although ERK1/2 and p38 are activated simultaneously in response to serum in JNK1,2-/- cells, the nuclear appearance of these kinases is different, with nuclear presence of ERK1/2 preceding p38. Notably, the nuclear appearance of phospho-ERK1/2 correlated with the ATF2-Thr71 phosphorylation, while nuclear translocation of phospho-p38 paralleled the detection of phosphoThr69+71 ATF2. In addition, treatment of JNK1,2-/- cells with SB203580, which abolished ATF2-Thr69+71 phosphorylation, also prevented nuclear appearance of phosphorylated $\mathrm{p} 38$. These results suggest that despite simultaneous activation of ERK1/2 and p38 by serum, their differential nuclear appearances can explain the differential kinetics of ATF2 phosphorylation.

The data presented in this study suggest that the serum-induced two-step mechanism of ATF2-phosphorylation in JNK-deficient cells is dependent on cooperation of ERK1/2 with p38. We propose that sequential nuclear appearance of these kinases is a determining factor driving this mechanism.

\section{Acknowledgements}

This work was funded by the Dutch Diabetes Research Foundation (grant 2001.00.46) and European Union COST Action BM0602

\section{References}

Baan, B., van Dam, H., Van Der Zon, G. C., Maassen, J. A., and Ouwens, D. M., 2006. The role of c-Jun N-terminal kinase, p38, and extracellular signalregulated kinase in insulin-induced Thr69 and Thr71 phosphorylation of activating transcription factor 2. Mol.Endocrinol.2006.Aug.;20.(8.):1786.-95 20, 1786-1795.

Ban, N., Yamada, Y., Someya, Y., Ihara, Y., Adachi, T., Kubota, A., Watanabe, R., Kuroe, A., Inada, A., Miyawaki, K., Sunaga, Y., Shen, Z. P., Iwakura, T., Tsukiyama, K., Toyokuni, S., Tsuda, K., and Seino, Y., 2000. Activating transcription factor-2 is a positive regulator in CaM kinase IV-induced human insulin gene expression. Diabetes 49, 1142-1148. 
Bhoumik, A., Lopez-Bergami, P., and Ronai, Z., 2007. ATF2 on the double activating transcription factor and DNA damage response protein. Pigment Cell Res. 20, 498-506.

Cuenda, A., Rouse, J., Doza, Y. N., Meier, R., Cohen, P., Gallagher, T. F., Young, P. R., and Lee, J. C., 1995. SB 203580 is a specific inhibitor of a MAP kinase homologue which is stimulated by cellular stresses and interleukin-1. FEBS Lett. 364, 229-233.

De Ruiter, N. D., Wolthuis, R. M., van Dam H., Burgering, B. M., and Bos, J. L., 2000. Ras-dependent regulation of c-Jun phosphorylation is mediated by the Ral guanine nucleotide exchange factor-Ral pathway. Mol.Cell Biol. 20, 84808488 .

Favata, M. F., Horiuchi, K. Y., Manos, E. J., Daulerio, A. J., Stradley, D. A., Feeser, W. S., Van Dyk, D. E., Pitts, W. J., Earl, R. A., Hobbs, F., Copeland, R. A., Magolda, R. L., Scherle, P. A., and Trzaskos, J. M., 1998. Identification of a novel inhibitor of mitogen-activated protein kinase kinase. J.Biol.Chem. 273, 18623-18632.

Hai, T. and Curran, T., 1991. Cross-family dimerization of transcription factors Fos/Jun and ATF/CREB alters DNA binding specificity. Proc.Natl.Acad.Sci.U.S.A 88, 3720-3724.

Hai, T. and Hartman, M. G., 2001. The molecular biology and nomenclature of the activating transcription factor/cAMP responsive element binding family of transcription factors: activating transcription factor proteins and homeostasis. Gene 273, 1-11.

Hai, T. W., Liu, F., Coukos, W. J., and Green, M. R., 1989. Transcription factor ATF cDNA clones: an extensive family of leucine zipper proteins able to selectively form DNA-binding heterodimers. Genes Dev. 3, 2083-2090.

Kyriakis, J. M. and Avruch, J., 2001. Mammalian mitogen-activated protein kinase signal transduction pathways activated by stress and inflammation. Physiol Rev. 81, 807-869.

Li, X. Y. and Green, M. R., 1996. Intramolecular inhibition of activating transcription factor-2 function by its DNA-binding domain. Genes Dev. 10, 517-527.

Livingstone, C., Patel, G., and Jones, N., 1995. ATF-2 contains a phosphorylationdependent transcriptional activation domain. EMBO J. 14, 1785-1797.

Mayr, B. and Montminy, M., 2001. Transcriptional regulation by the phosphorylationdependent factor CREB. Nat.Rev.Mol.Cell Biol. 2, 599-609.

Morton, S., Davis, R. J., and Cohen, P., 2004. Signalling pathways involved in multisite phosphorylation of the transcription factor ATF-2. FEBS Lett. 572, 177-183.

Ouwens, D. M., De Ruiter, N. D., Van Der Zon, G. C., Carter, A. P., Schouten, J., Van Der Burgt, C., Kooistra, K., Bos, J. L., Maassen, J. A., and van Dam, H., 2002. Growth factors can activate ATF2 via a two-step mechanism: phosphorylation of Thr71 through the Ras-MEK-ERK pathway and of Thr69 through RalGDS-Src-p38. EMBO J. 21, 3782-3793.

Raingeaud, J., Gupta, S., Rogers, J. S., Dickens, M., Han, J., Ulevitch, R. J., and Davis, R. J., 1995. Pro-inflammatory cytokines and environmental stress cause p38 mitogen-activated protein kinase activation by dual phosphorylation on tyrosine and threonine. J.Biol.Chem. 270, 7420-7426.

Rouse, J., Cohen, P., Trigon, S., Morange, M., Alonso-Llamazares, A., Zamanillo, D., Hunt, T., and Nebreda, A. R., 1994. A novel kinase cascade triggered by stress 
and heat shock that stimulates MAPKAP kinase-2 and phosphorylation of the small heat shock proteins. Cell 78, 1027-1037.

Sabapathy, K., Hochedlinger, K., Nam, S. Y., Bauer, A., Karin, M., and Wagner, E. F., 2004. Distinct roles for JNK1 and JNK2 in regulating JNK activity and cJun-dependent cell proliferation. Mol.Cell 15, 713-725.

Sakurai, A., Maekawa, T., Sudo, T., Ishii, S., and Kishimoto, A., 1991.

Phosphorylation of cAMP response element-binding protein, CRE-BP1, by cAMP-dependent protein kinase and protein kinase $\mathrm{C}$.

Biochem.Biophys.Res.Commun. 181, 629-635.

Sanders, J., Brandsma, M., Janssen, G. M., Dijk, J., and Moller, W., 1996. Immunofluorescence studies of human fibroblasts demonstrate the presence of the complex of elongation factor- 1 beta gamma delta in the endoplasmic reticulum. J.Cell Sci. 109, 1113-1117.

Sevilla, A., Santos, C. R., Vega, F. M., and Lazo, P. A., 2004. Human vaccinia-related kinase 1 (VRK1) activates the ATF2 transcriptional activity by novel phosphorylation on Thr-73 and Ser-62 and cooperates with JNK. J.Biol.Chem. 279, 27458-27465.

van Dam, H. and Castellazzi, M., 2001. Distinct roles of Jun : Fos and Jun : ATF dimers in oncogenesis. Oncogene 20, 2453-2464.

van Dam, H., Wilhelm, D., Herr, I., Steffen, A., Herrlich, P., and Angel, P., 1995. ATF-2 is preferentially activated by stress-activated protein kinases to mediate c-jun induction in response to genotoxic agents. EMBO J. 14, 1798-1811.

Vlahopoulos, S. A., Logotheti, S., Mikas, D., Giarika, A., Gorgoulis, V., and Zoumpourlis, V., 2008. The role of ATF-2 in oncogenesis. Bioessays 30, 314327.

Waas, W. F., Lo, H. H., and Dalby, K. N., 2001. The kinetic mechanism of the dual phosphorylation of the ATF2 transcription factor by p38 mitogen-activated protein (MAP) kinase alpha. Implications for signal/response profiles of MAP kinase pathways. J.Biol.Chem. 276, 5676-5684. 


\section{Figure legends}

Fig. 1. Identification of ERK1/2 and p38 as the major ATF2 kinases activities in JNK -/- cells. (A) JNK1,2-/- cells, pretreated with vehicle (solid line) or U0126 (dashed line) for 15 minutes, were FCS stimulated for 10 minutes before lysis. MonoQ anion exchange-fractionation was performed on these lysates and the obtained fractions were used in an ATF2-directed in vitro kinase assay using GST-ATF2 as substrate. ATF2-Thr71 specific phosphorylation of GST-ATF2 was determined by Western blotting using the ATF2-Thr71 phospho-specific antibody. Relative ATF2-Thr71 reactivity was plotted against MonoQ fraction number. The presence of phosphoERK1/2 and p38 MAPK in the different fractions was determined by western blotting. (B) The p38-containing MonoQ fraction (\#17) was used in an in vitro kinase assay in the presence of vehicle or SB203850 with GST-ATF2 as the substrate. ATF2-Thr71 specific phosphorylation of GST-ATF2 was determined by Western blotting using a ATF2-Thr71 phospho-specific antibody.

Fig. 2. Inhibition of ERK1/2 and p38 differentially abrogates ATF2-Thr71 and ATF2Thr69+71 phosphorylation in serum-stimulated JNK1,2 -/- cells. (A) Serum-starved JNK1,2-/- cells were treated with $20 \%$ fetal calf serum (FCS). Total cell lysates were prepared at indicated time-points and analyzed by Western blotting using phosphospecific ATF2-Thr71, and ATF2-Thr69+71 antibodies. (B) Serum-starved JNK1,2-/cells were pre-incubated with vehicle or inhibitors U0126 or SB203580 before serum-stimulation (FCS; 20\%) for the times indicated. ATF2-Thr71- and Thr69+71phosphorylation levels were determined by immunoblotting with specific antibodies. (C) The relative ATF2-Thr71 phosphorylation of the vehicle, U0126 and SB203580treated lysates were quantified and plotted against the time of stimulation. (D) Serumstarved JNK1,2-/- cells were treated with carrier, U0126 or SB203580, FCSstimulated for 8 minutes and lysed as described above. ERK1/2 and MAPKAPK-2 phosphorylation was determined by immunoblotting.

Fig. 3. Regulation of ATF2 phosphorylation by the Ras-Raf-MEK-ERK1/2- and the Ras-Rlf-p38 pathway in JNK1/2-/- cells. (A) Total cell lysates of JNK1,2-/- cells transiently transfected with either empty vector (-), RafCAAX, RasL61, or RlfCAAX were analyzed by Western blotting using phospho-specific ATF2-Thr71, ATF2Thr69+71, and p38 antibodies. Expression levels of HA-tagged proteins were verified by reprobing the stripped filters with HA-antibodies. (B) Effect of RasL61 and RlfCAAX on a GAL4-ATF2 (open bars) and GAL4-ATF2-T69/71A dependent (closed bars) luciferase reporter. Data are expressed as mean \pm SEM relative luciferase activity of 3 independent experiments performed in duplicate. (C) In vitro ATF2phosphorylation by ERK (\#12) and p38 (\#17) containing monoQ fractions. Equal loading of GST-ATF2 was verified by immunonoblotting with GST antibodies.

Fig. 4. Serum-induced ATF2-Thr69+71, but not Thr71-phosphorylation is SB203580sensitive in JNK1,2-/- cells. Serum-starved JNK1,2-/- cells were treated with SB203580 (SB) for 30 minutes prior to stimulation with 20\% serum (FCS) for 8 minutes. Cells were fixed and stained with antibodies for (A) Thr71- or (B) Thr69+71-phosphorylated ATF2 followed by FITC-conjugated secondary antibodies (green). DNA was stained with DAPI (blue). 
Fig. 5. The onset of ATF2-Thr71 and ATF2-Thr69+71-phosphorylation coincides with the appearance of phospho-ERK1/2 and -p38 in nuclear fractions (A) Lysates from serum-starved JNK1,2-/- cells prepared at the indicated time points after FCS stimulation were examined for phosphorylation of ERK1/2 and p38 and ATF2-Thr71 and Thr69+71 by immunoblotting with phospho-specific antibodies as described. (B) Serum-starved JNK1,2-/- cells were serum-stimulated as described, at the times indicated cellular fractions were prepared and the nuclear fractions examined for phosphorylation of ERK1/21/2 and p38 and ATF2-Thr71 and Thr69+71 by immunoblotting with phospho-specific antibodies as described. (C) Serum-starved JNK1,2-/- cells were serum-stimulated as described, at the times indicated cellular fractions were prepared and the purity of both cytosolic (CF) and nuclear (NF) fractions was examined by immunoblotting with Elongation Factor (EF)-1 beta and Lamin A-specific antibodies.

Fig. 6. The onset of ATF2-Thr71 and ATF2-Thr69+71-phosphorylation coincides with nuclear translocation of phospho-ERK1/2 and phospho-p38. (A) Serum-starved JNK1,2-/- cells were stimulated with $20 \%$ serum (FCS) and fixed at the times indicated. The fixed cells were stained with antibodies for phospho-ERK1/2 (ERK1/2PP) or phospho-p38 (p38-PP) followed by FITC-conjugated secondary antibodies (green). DNA was stained with DAPI (blue). (B) Serum-starved JNK1,2-/- cells pretreated with vehicle or SB203850 for 30 minutes prior to 8 minute FCS-stimulation were fixed and stained for phospho-p38 (p38-PP) as described above. (C) Serumstarved JNK1,2-/- cells, pre-treated with vehicle or SB203850 were serum-stimulated for 8 minutes, after which cellular fractions were prepared and the nuclear fractions examined for p38- and ATF2-Thr69+71 phosphorylation by immunoblotting with phospho-specific antibodies as described. 
Figure 1

A

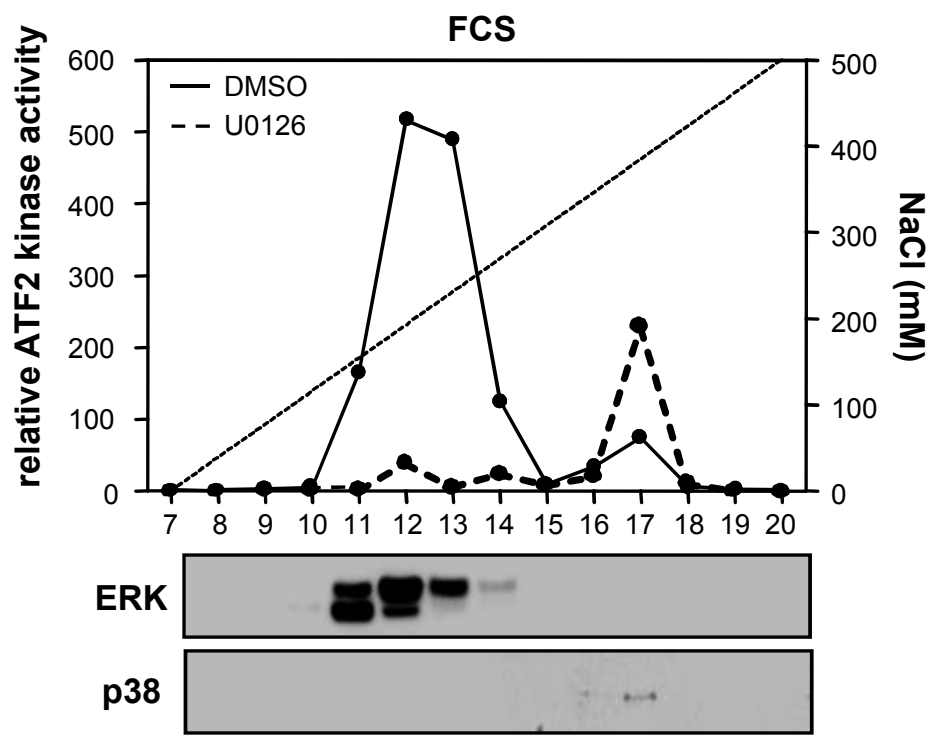

B

MonoQ fraction $\mathrm{nr} 17$

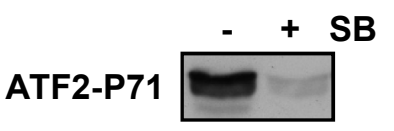




\section{Figure 2}

A

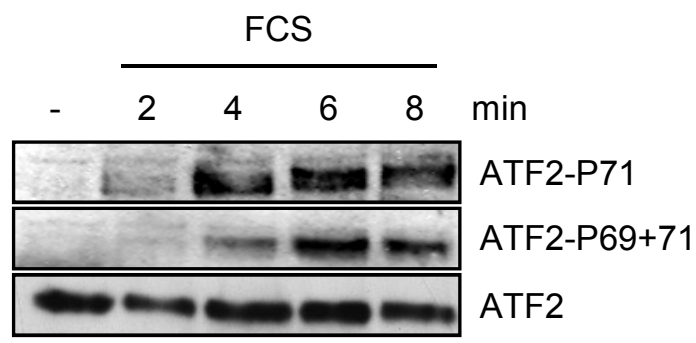

B

\begin{tabular}{|c|c|c|c|c|c|c|c|c|c|c|}
\hline \multirow[b]{2}{*}{ - } & \multirow[b]{2}{*}{4} & \multirow[b]{2}{*}{8} & \multicolumn{3}{|c|}{ + U0126 } & \multicolumn{3}{|c|}{ + SB203580 } & \multirow{2}{*}{\multicolumn{2}{|c|}{$\min$ FCS }} \\
\hline & & & - & 4 & 8 & & & & & \\
\hline & $=$ & $=$ & 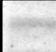 & $=$ & $=$ & & & 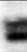 & & ATF2-P71 \\
\hline & & $m$ & & $m$ & - & & & & & ATF2-P69+71 \\
\hline 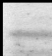 & - & $\bar{z}$ & - & - & $\bar{z}$ & & & & & ATF2 \\
\hline
\end{tabular}

C

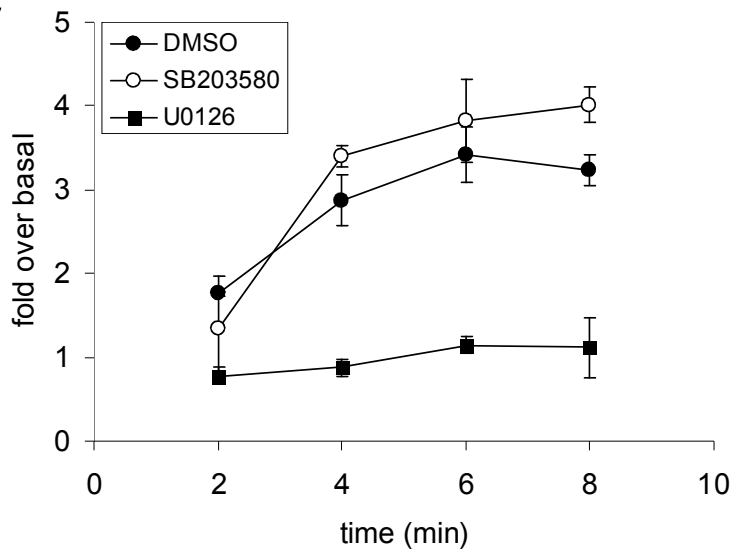

D

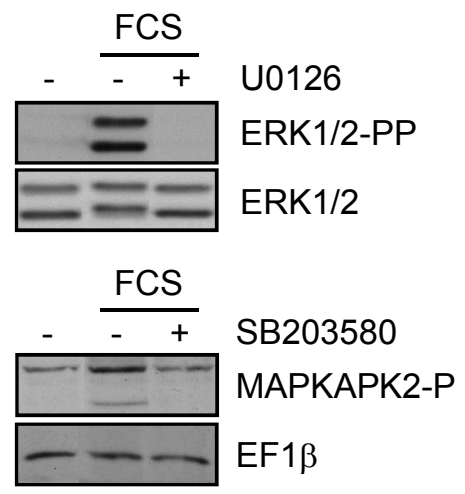




\section{Figure 3}

A

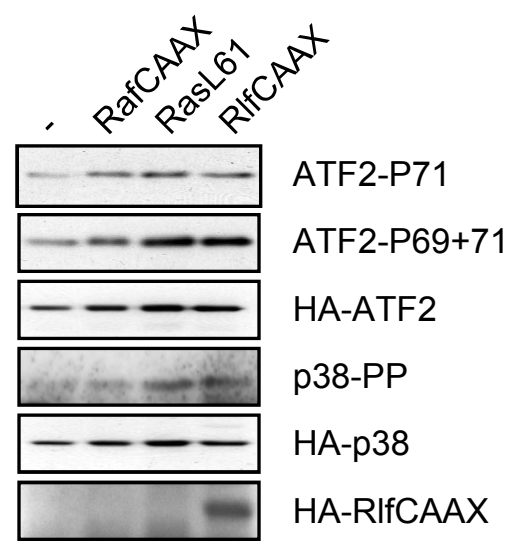

B

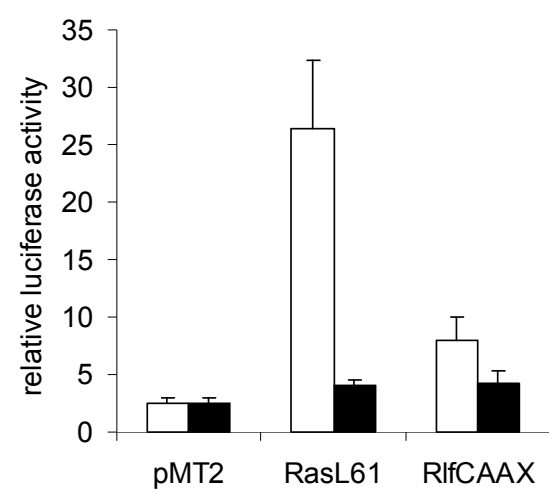

C

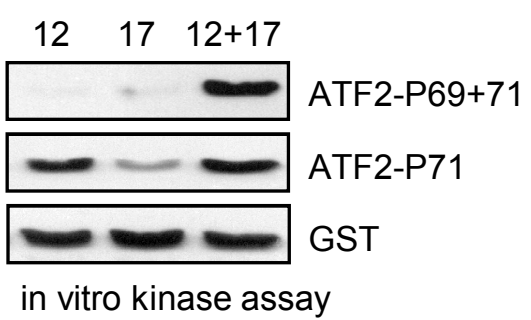


Figure 4

A

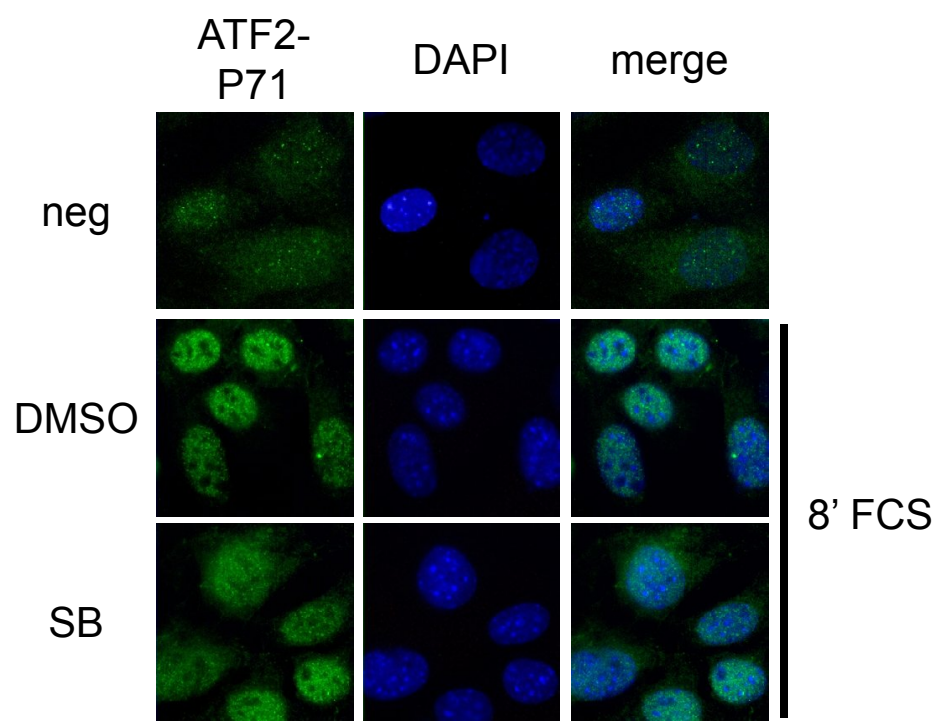

B

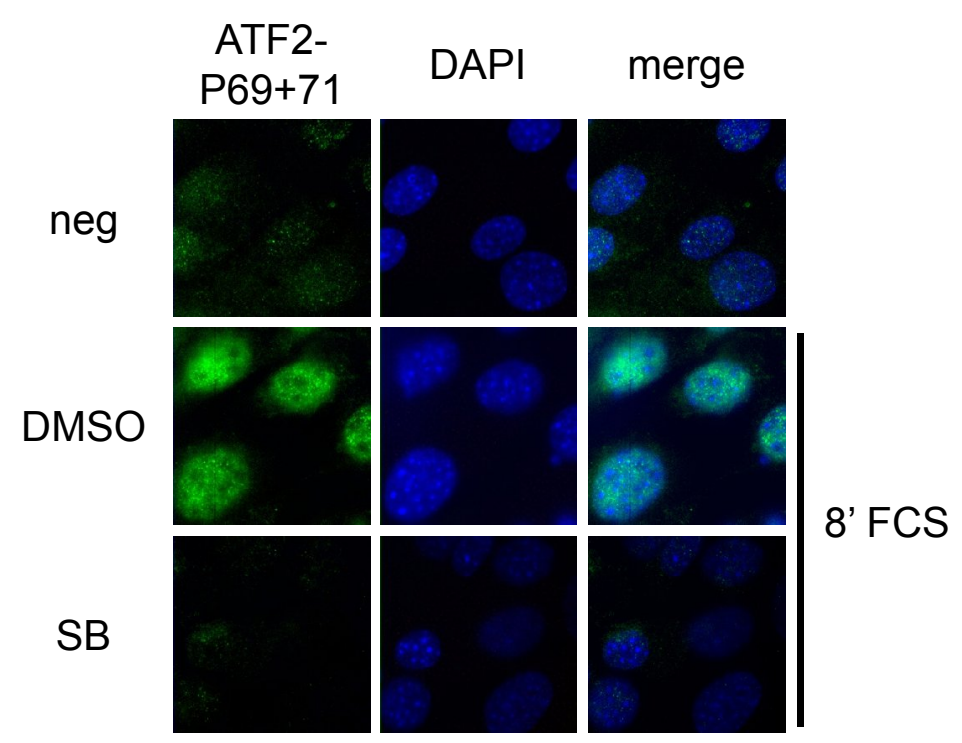


Figure 5

A

B
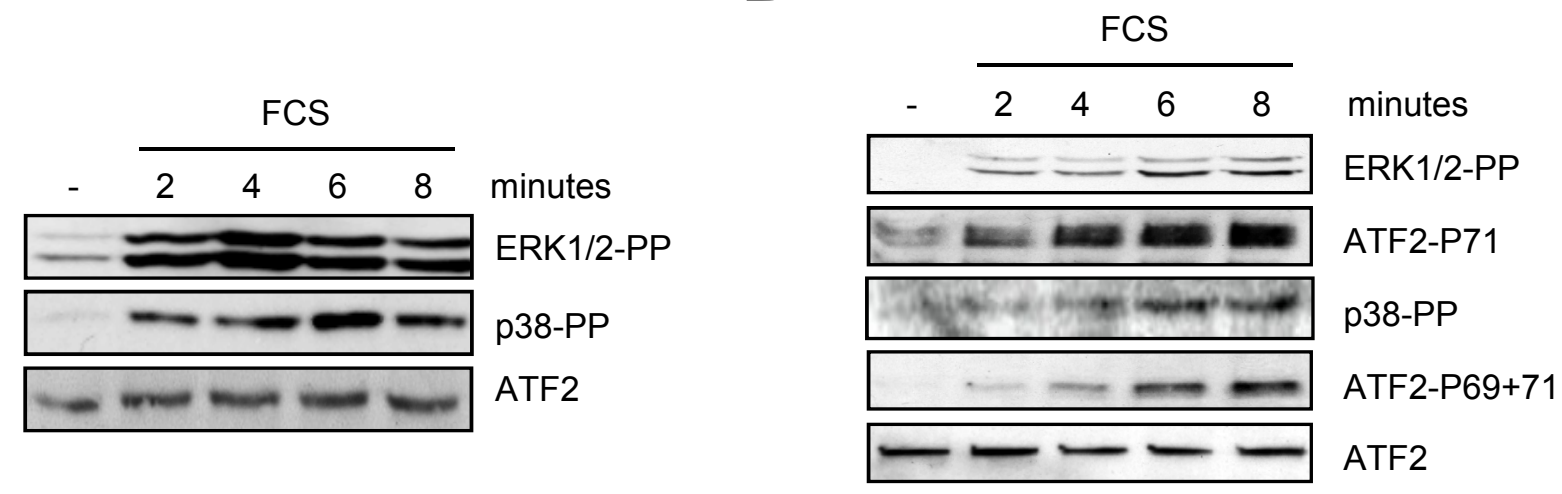

Nuclear Fractions

C

\begin{tabular}{|c|c|c|c|c|c|c|c|c|c|c|}
\hline \multicolumn{5}{|c|}{ CF } & \multicolumn{5}{|c|}{ NF } & \multirow[b]{2}{*}{ minutes FCS } \\
\hline- & 2 & 4 & 6 & 8 & - & 2 & 4 & 6 & 8 & \\
\hline- & 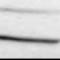 & 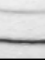 & - & 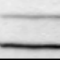 & & & $=$ & - & $=$ & Lamin \\
\hline 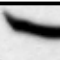 & - & & & $\ldots$ & & & & & & EF1 $\beta$ \\
\hline
\end{tabular}




\section{Figure 6}

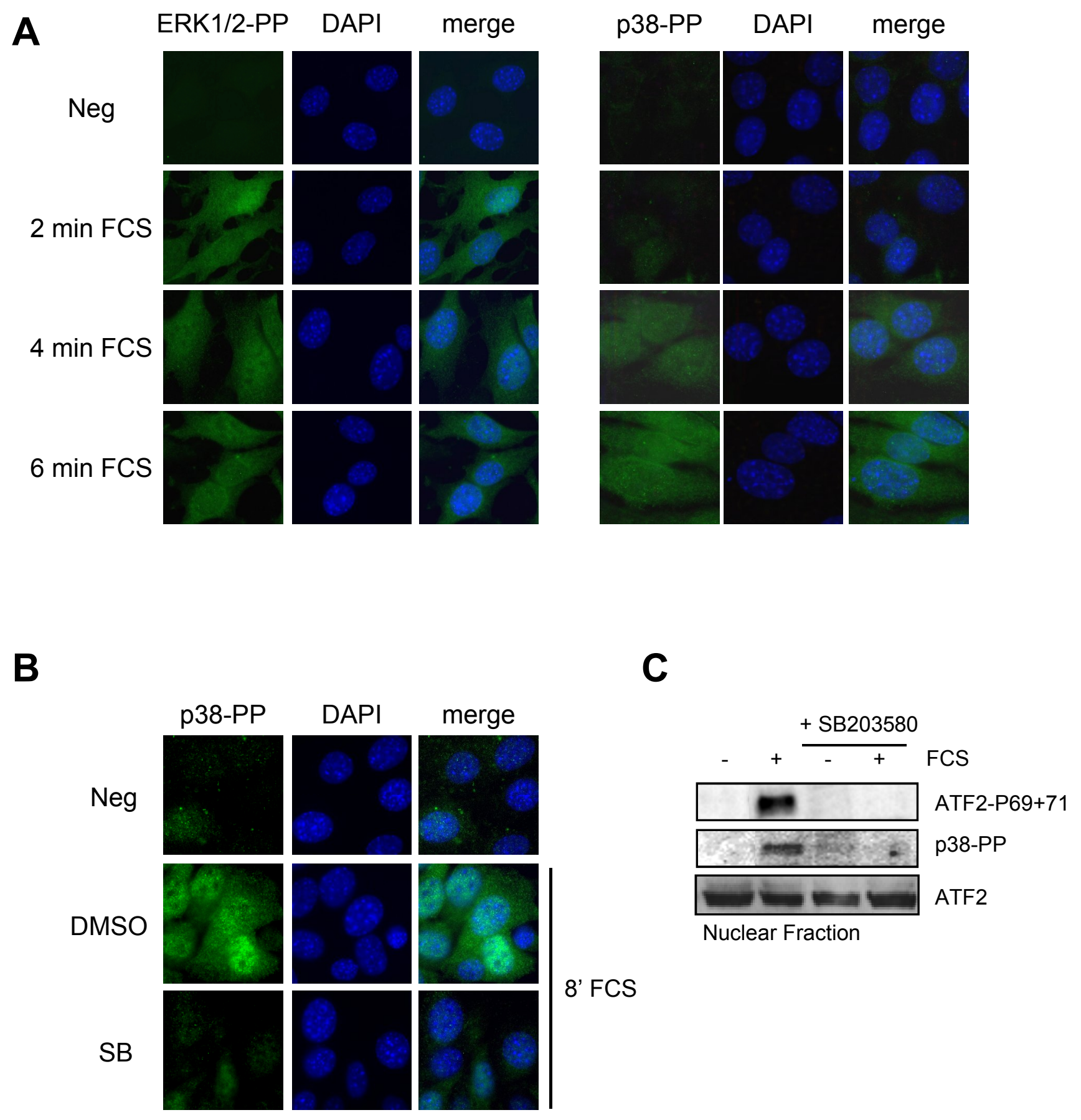

